\title{
THE CONTROLLED ELECTRIC DRIVE OF THE AUTOMATIC COOLING SYSTEM OF THE ENGINE ROOM ON A VESSEL
}

\author{
Dennis V. Bevz ${ }^{1, *}$, Lubov A. Payuk ${ }^{1}$, and Nataliya A. Voronina ${ }^{1}$ \\ ${ }^{1}$ Tomsk Polytechnic University, 634050 Tomsk, Russia
}

\begin{abstract}
Development of an automatic cooling system control by the Zelio Logic controller. Development of the simulation model of the openloop system "frequency inverter - asynchronous motor with IRcompensation" in Matlab Simulink. Analysis of the transient characteristics $\omega=f(t), M=f(t)$ at the start of the asynchronous motor.
\end{abstract}

\section{Introduction}

The Engine room it is a room on board designed to accommodate machines and mechanisms for its moving [1].

In this room there are:

- the central control post, which derived all automation systems, control and alarm systems

- main engine, which rotates the rowing screw;

- electric motors, intended to generate electricity for lighting, heating, operation of various devices and mechanisms;

- $\quad$ pumps for supplying oil, liquid fuel, cooling water;

- separators intended for clarification fuel and oil from impurity;

- compressors, which compress air supplied for engines starting;

- steam boiler intended for heating, heating of liquid cargo, for technological needs.

The engine room is presented in figure 1.

The ventilation system of the engine room has two main objectives:

- to provide such an environment that will allow machines and mechanisms work reliably;

- to provide comfortable working conditions for staff.

Heat that is emitted from the engine and other mechanisms of the machine room, absorbed by the surface of the engine room. Part of the heat transferred to the atmosphere or water through the hull. The remaining heat has to be removed by the cooling system. Place the input of outside air into the engine room should be located as far away from heat sources and as low as possible. Since heat causes the air to rise upwards, the air outlet should be done at the highest point of the engine room.

* Corresponding author: d.v.bevz@mail.ru 


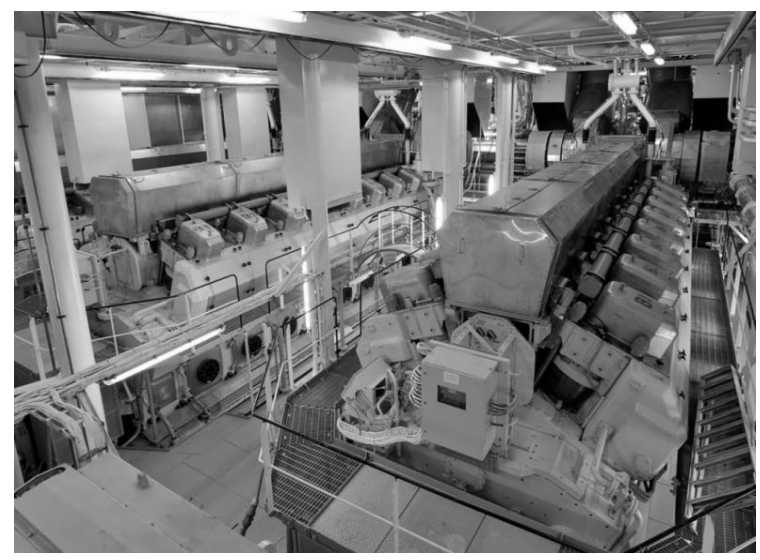

Fig. 1. The engine room of a vessel.

\section{Development of automatic control of the cooling system}

A functional diagram of automatic ventilation system is presented in figure 2 [2].

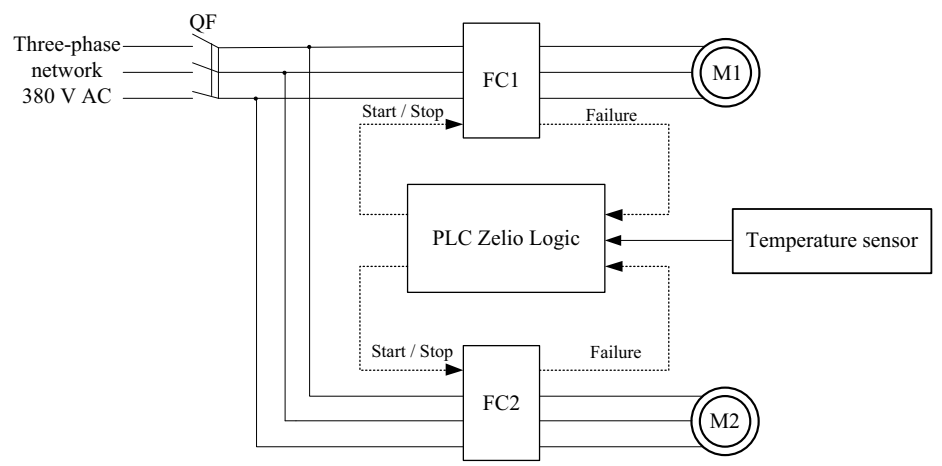

Fig. 2. Functional diagram of automatic cooling system: QF - the automatic circuit breaker, FC1 the main frequency inverter, FC2 - the reserve frequency inverter, M1 - the main asynchronous motor, M2 - the reserve asynchronous motor PLC - the programmable logic controller Zelio Logic of Schneider Electric.

This system has two asynchronous motors. The first motor is main and the second motor is reserve. The temperature sensor has analog output in the range $0 \ldots 10 \mathrm{~V}$ which corresponds to a temperature range from 0 to 100 degrees Celsius. Analog output of temperature sensor connects to analog input of PLC. When the temperature rises exceeds 30 degrees Celsius PLC generates a start signal which comes from the digital output of the controller to the digital input of the first frequency inverter, then the main asynchronous motor is started and ventilation process is begins. Ventilation continues until the temperature of 20 degrees Celsius and then the PCL generates stop signal to the first inverter. In case of a malfunction of the main frequency inverter a fault signal is entered to the PLC digital input. The controller sends a stop signal to the first frequency inverter and a start signal to the second frequency inverter. If the temperature during the operation of the main asynchronous motor exceeds the preset critical value equals 40 degrees Celsius the controller will generate start signal to the reserve frequency inverter and then the reserve asynchronous motor is started. The standby motor is operated together with the main motor for a predetermined time interval. If after that time interval the temperature does not 
decrease alarm is triggered. The developed algorithm [3] that explains the operations of automatic cooling system is presented in figure 3 .

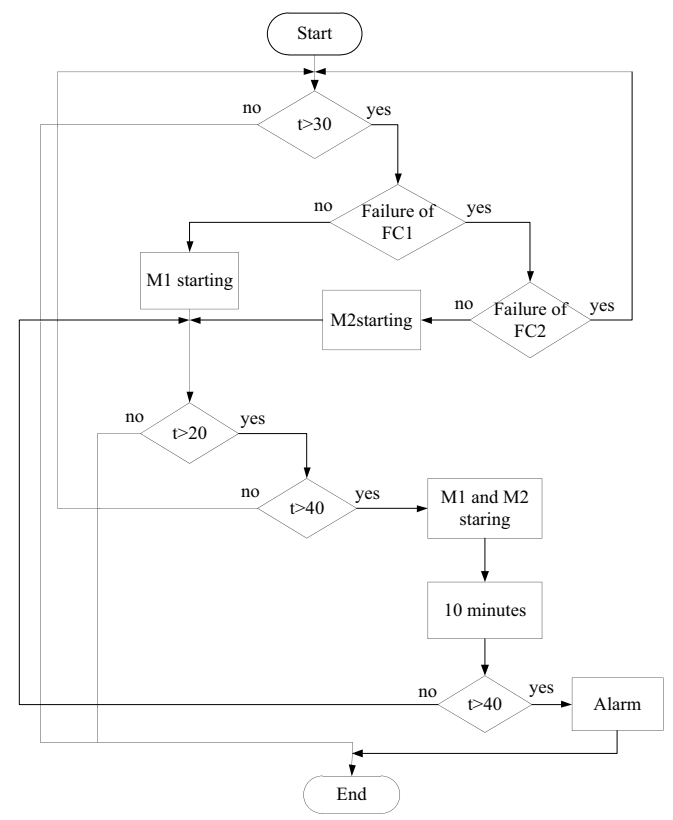

Fig. 3. The algorithm of the operation of the automatic cooling system.

The algorithm is written for the controller in the functional block diagram language. The exterior of the software window of the controller with algorithm [4] is shown in Fig. 4.

The developed algorithm provides work of the system of cooling in 3 modes:

1. start the main motor when the temperature exceeds the set value;

2. start the backup motor if there is an accident at the first frequency inverter and the temperature exceeds the set value;

3. operation of both motors for a predetermined time interval.

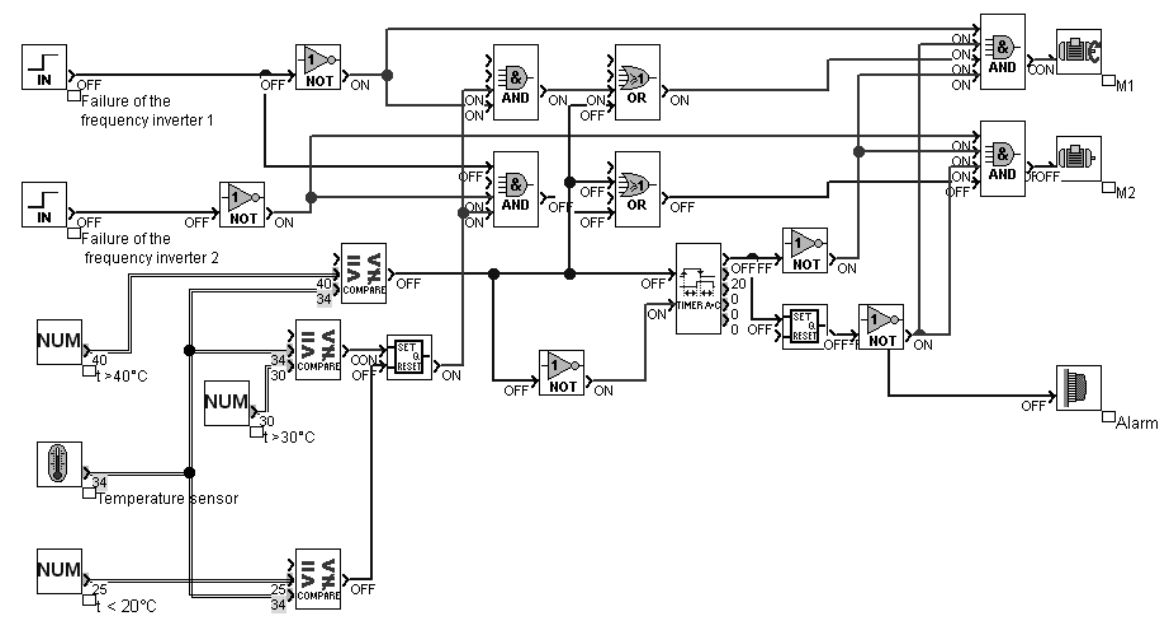

Fig. 4. The exterior of the software window of the PLC. 


\section{Development of a simulation model of the open-loop system "frequency inverter - asynchronous motor with IR- compensation"}

To control the speed of the electric drive is used scalar control law $-U / f=$ const. The simulation model of the open-loop system "frequency inverter - asynchronous motor with IR-compensation" is created in Matlab Simulink 2012 and presented in figure 5 [5].

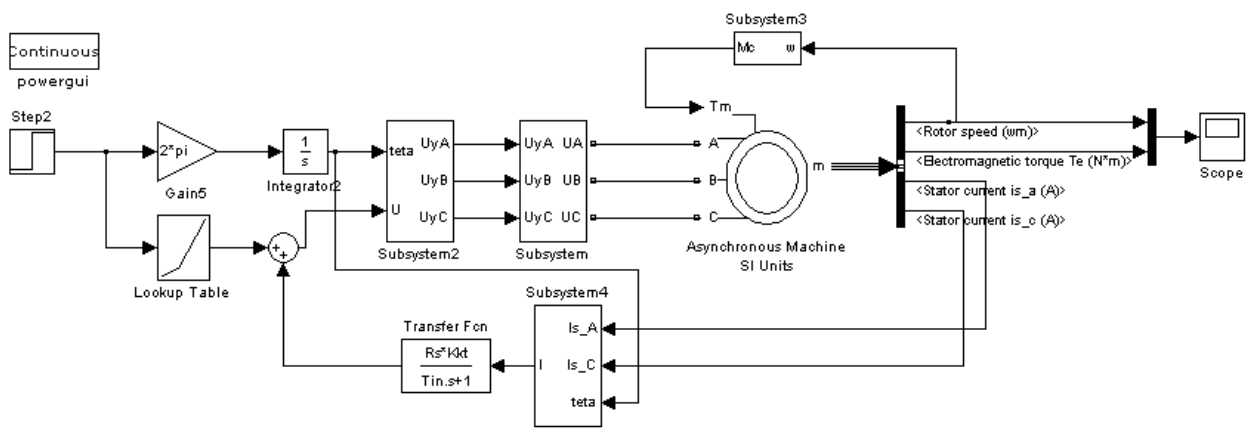

Fig. 5. The simulation model of the open-loop system "frequency inverter - asynchronous motor with IR-compensation".

Block "Lookup Table" forms the required relationship of the scalar control between the frequency and voltage $[6,7]$. It sets the received frequency regulation law. The control signal is entered to the direct coordinate converter (block subsystem 2). Three sine wave control voltages $\mathrm{U} 1 \mathrm{yA}, \mathrm{U} 1 \mathrm{yB}, \mathrm{U1yC}$ which are shifted relative to each other at an angle $\pm 2 * \mathrm{pi} / 3$ with amplitudes proportional to the control voltage are formed at the output of the converter. The signals U1yA, U1yB, U1yC form phase output voltage of the autonomous voltage (block subsystem). The transient characteristics of speed and torque are presented in figure 6.
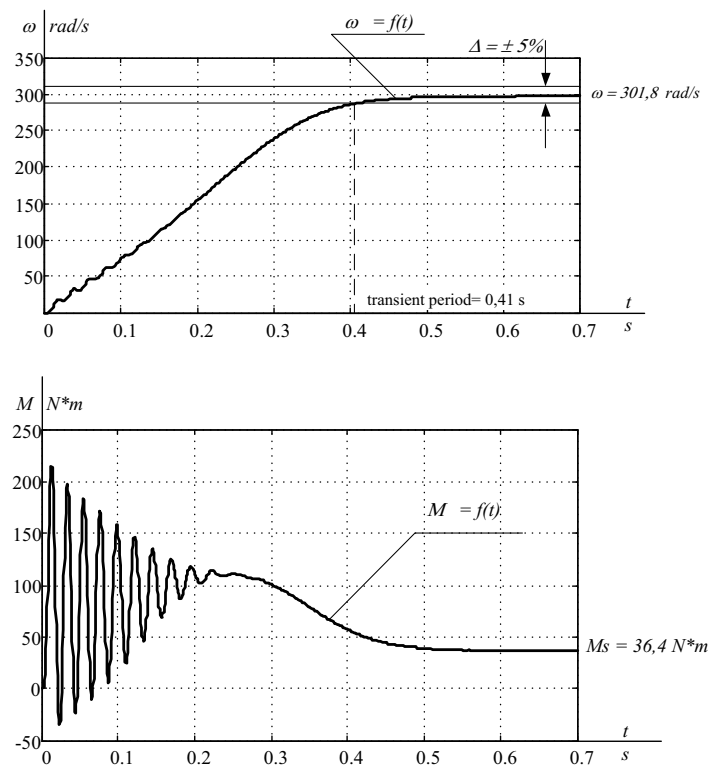

Fig. 6. The transient characteristics $\omega=f(t), M=f(t)$. 


\section{Conclusion}

The designed automatic cooling system of the engine room on a vessel has a high reliability, is simple in service and economic:

1. the system has two asynchronous motors one of them is main motor and another one is backup motor. The control of the asynchronous motors is provided by the programmable logic controller Zelio Logic depending on the signal from the tempearture sensor and the faulire signal from frequency inverters;

2. start and stop of the asynchronous machines are relized by the frequency inverters, which allow to relize smooth start of the motors. It leads to reduction of starting currents and therefore increases life cycle of the asynchronous motors. Also, use of the frequency inverter leads to saving of electricity.

\section{References}

1. N. F. Emelyanov, Design, construction and elements of the theory of vessel (Dalrybvtuz, Vladivostok, 2002) [in Russia]

2. M.P. Belov, A.D. Novikov, L.N. Rassudov, Automatic electric drive of industrial machinery and technological complexes (Academa, Moscow, 2007) [in Russia]

3. E.P. Ugrumov, Digital circuitry, (BHV-Petersburg, St. Petersburg, 2007) [in Russia]

4. R. Coris, X. Schmidt-Walter, Reference circuit design engineer (Technosphere, Moscow, 2008) [in Russia]

5. L.S. Udut, O.P. Maltseva, N.V. Koyain, Asynchronous frequency controlled electric drive (Publisher of Tomsk Polytechnic University, Tomsk, 2009) [in Russia]

6. I.V. Chernyh., Simulation of electrical devices in MATLAB, SimPowerSystems and Simulink (Piter, St. Petersburg, 2007) [in Russia]

7. L. Payuk, N. Voronina, S. Korepanov, O. Galtseva, N. Natalinova, MATEC Web of Conf. 79, 01060 (2016) 